\title{
História, moral e patriotismo: recortes de uma época no álbum do grupo escolar Lauro Müller(1910-1930) * 1
}

\author{
Flávio Welker Gentil ${ }^{2}$
}

Cristiani Bereta da Silva ${ }^{3}$

\begin{abstract}
Resumo: $O$ presente trabalho objetiva analisar as representações sobre o civismo e patriotismo no Álbum do Grupo Escolar Lauro Müller. Este álbum foi construído pelos diretores e preenchido com reportagens que saíam em jornais e convites para as festividades escolares, ambos relativos ao Grupo Escolar Lauro Müller, fundado em 1912, na cidade de Florianópolis. O recorte temporal, apesar de o documento constar com reportagens até os anos de 1960, será mantido até a década de 1930. A escolha para este recorte se baseia na cultura escolar observada no início da década de 1910 e a de 1930 que passava pela formação moral e patriótica do cidadão, o que se percebe pelos recortes. A partir disso, questionou-se quais forças os envolviam para o ato de guardar o cotidiano escolar: seria pela crença em seu trabalho civilizador realizado no Grupo Escolar?

Palavras-chave: Grupos Escolares; Ensino de História; Cultura Escolar.
\end{abstract}

Abstract: This paper analyzes the Album of the School Group Lauro Müller. This album was built by the directors and filled with stories that came out in newspapers and invitations to the festivities school, both on the Lauro Müller Elementary School established in 1912. The time frame, even though the document contained in reports to the year 1960, will be maintained until the 1930s. The choice of this cut is based on the school culture observed at the beginning of the 1910 and 1930 that passed by the formation of moral and patriotic citizen, what is perceived by cuttings. From this, which questioned whether the forces involved in the act of saving the school routine, would be the belief in their civilizing work done in the primary school?

Keywords: School Groups; Teaching History; Culture School.

\footnotetext{
* Artigo submetido em 05 de novembro de 2012 e aceito para publicação em 27 de janeiro de 2013.

${ }^{1}$ Este artigo constitui recorte da pesquisa de mestrado de Flávio Welker Gentil desenvolvida no PPGH/UDESC. Tal pesquisa, por sua vez, relaciona-se a uma investigação mais abrangente intitulada: "Nação e Região: uma leitura a partir das culturas políticas e das políticas para o ensino de História em Santa Catarina nas décadas de 1930 a 1940" coordenada pela professora Cristiani Bereta da Silva e realizada pelo grupo de pesquisa Ensino de História, Memória e Culturas com financiamento do CNPq.

${ }^{2}$ Bacharel e Licenciado em História. Aluno do Mestrado em História do Programa de Pós-Graduação em História da UDESC. Bolsista PROMOP, pesquisador do Grupo de Pesquisa Ensino de História Memória e Culturas, vinculado a Laboratório de Ensino de História - LEH/UDESC. E-mail: gentil7@ hotmail.com.

${ }^{3}$ Doutora em História. Professora do Departamento de História e dos Programas de Pós-Graduação em História e em Educação. Bolsista Produtividade do CNPq, coordenadora do Grupo de Pesquisa Ensino de História Memória e Culturas, vinculado a Laboratório de Ensino de História - LEH/UDESC. Email: cristianibereta@gmail.com.
} 


\section{Com Tempo de Mistónias}

\section{Introdução}

O presente trabalho objetiva analisar representações sobre a história, o civismo e o patriotismo no início do século XX nas páginas do Álbum do Grupo Escolar Lauro Müller. Este álbum foi construído pelos diretores da instituição e preenchido com reportagens que saíam em jornais e convites para as festividades escolares, ambos relativos ao Grupo Escolar Lauro Müller fundado em 1912, o segundo mais antigo de Santa Catarina. O recorte temporal deste trabalho vai desde a fundação do Grupo até a década de 1930, muito embora o documento traga reportagens até a década de 1960. A escolha para este recorte se baseia na cultura escolar observada no início da década de 1910 e a de 1930 que passava pela formação moral e patriótica do cidadão republicano, no ainda recente regime, o que se percebe pela escolha dos temas festivos e dos personagens comemorados.

A pretensão do texto não é alcançar o real, mas lançar mão a demais possibilidades para a escrita da história. Já que nos padrões metodológicos da história "os objetos e as experiências são produtores de nosso modo de experimentar, determinado no tempo e no espaço" (ALBUQUERQUE, 2007, p.60). Logo, a história vira uma contínua invenção do passado pelo efêmero presente. O que mal foi produzido com a pretensão de verdade, já está sendo desfeito para surgirem novas produções do passado (ALBUQUERQUE, 2007).

Procura-se é buscar nas diferentes formas de apropriação, voz para as singularidades que muitas vezes não se é encontrada na história da educação em Santa Catarina. Normalmente, através da visão do macro se mostra um estado catarinense voltado para as tendências educacionais paulistas e a sua passividade em importar os elementos da modernização da educação deste Estado (SILVA; TEIVE, 2009). E é esse o território explorado neste texto.

Os documentos utilizados para esse texto foram retirados do Museu da Escola Catarinense, uma instituição que conta com um vasto acervo sobre o processo de escolarização do Estado, assim como, livros, biografias e enciclopédias (CUNHA, 2009). O documento em questão foi doado ao museu recentemente pela comemoração do centenário do Grupo Escolar Lauro Müller, hoje Escola Estadual Básica Lauro Müller, portanto, chegando "fresco" às minhas mãos o álbum organizado pelos diretores da escola. Também se escolheu 


\section{Com Tempo de Mistónias}

dar voz a documentos oficiais como os Programas dos Grupos Escolares da década de 1910 e 1930.

Para a escrita do texto se pretende analisar a Instituição escolar a partir da proposta de Cultura Escolar, isso significa que a escola será vista como um local propício para criar um imaginário coletivo, ensinar determinados conhecimentos e inculcar condutas (FARIA et. al., 2004), isso será percebido através da proposta de recorte temporal historicamente delimitado, décadas de 1910 e 1920. A cultura escolar também deve ser entendida, não apenas dentro da escola, mas criada ao entorno dela, envolto em uma cultura específica (FARIA et. al., 2004), no caso a modificação da relação com o corpo social e a nova cultura política republicana que estava se moldando. A escola se mostra como uma das diversas instituições que será modernizada no período republicano, e, portanto, será percebida como um desses vários movimentos que infligem simultaneamente no corpo e na mente dessa sociedade por uma conduta aburguesada, saneada e patriótica.

O documento analisado é descrito por seus atores, os diretores da instituição, como Álbum do Grupo Escolar Lauro Müller, ele é preenchido com recortes das reportagens que saíam em diversos jornais ${ }^{4}$ da época relativos ao Grupo Escolar Lauro Müller e com os convites das festividades escolares. Assim, transforma-se em uma espécie de retrato dos momentos em que a instituição passava, sendo possível seguir o cotidiano e as transformações escolares, resguardando o cotidiano e os acontecimentos marcantes do esquecimento. $\mathrm{O}$ ato de guardar evidenciado pelos diretores do Grupo Escolar pode ser pensado a partir das análises de Ângela de Castro Gomes (GOMES, 2004: 16), ou seja, como um meio da "constituição de uma memória de si, realizada pelo recolhimento de objetos materiais, com ou sem a intenção de resultar em coleções”. Uma construção de memória que, no caso do “Álbum”, trespassa por suas condições de diretores do Grupo Escola Lauro Müller e a própria cultura escolar que a época a instituição almejava alcançar, formando um elo identitário como portadores da civilidade republicana. Portanto, dentro deste laço, os atores optam todos por guardar as

\footnotetext{
$4 \quad$ Os materiais recortados e guardados relativos aos jornais constam na maioria do jornal O Dia, mas também constam as notícias retiradas do jornal Época, Folha do Comércio, A República, d'Oriente e O Estado, jornais que circularam em Florianópolis nas décadas de 1910, 1920 e 1930, sendo o mais novo desses a entrar no "álbum" e em circulação o jornal $O$ Estado, que apenas aparece entre os outros recortes em 1915.
} 
comprovações do lugar memória que seria estabelecido diante ao grande público, as notícias de jornais sobre o Grupo. O que faz se entender que a opção por estes documentos não foi dada à toa, mas, como coloca Philippe Artières (1998, p.11), no ato do arquivamento, "fazemos um acordo com a realidade, manipulamos a existência: omitimos, rasuramos, sublinhamos, damos destaques a certas passagens", a prática de arquivar nunca é neutra e imparcial. Eles se colocam como estes símbolos do republicanismo e da modernização em Santa Catarina, a partir dos objetos recolhidos, garimpados, recortados, colados, enfeitados e sublinhados.

Os recortes têm início com o seu primeiro Diretor Luiz Pacífico das Neves, em 1912, e tem o término súbito na década de 1960 com as reportagens do seu quinquagésimo aniversário, que é muitíssimo comentado, três páginas inteiras do jornal $O$ Estado de Santa Catarina. Neste texto, busca-se tratar dos momentos que estão ali presentes nos documentos, deixando o silêncio deles após a década de 1960 para uma posterior discussão.

Assim, para tratar de tais fontes, o presente trabalho tem como aportes conceituais a história cultural da escrita, pelo objeto em que se estabeleceu para a pesquisa e a cultura escolar, que pensa o momento em que está sendo escrito dentro da instituição. O que demonstra, de acordo com Ângela de Castro Gomes (2004), a interação que foi possível e vem sendo utilizada pela história da educação as novas abordagens da história cultural. Um recorte temático que pertenceria à história da escrita, tomando o Álbum como objeto central e principal, passa a interagir com a história da cultura escolar. Embora, como mesmo comenta a autora, tais perspectivas de se trabalhar com a história da escrita só comecem a ser entendidas como fontes privilegiadas apenas recentemente.

Para a argumentação deste texto - que visa delinear as formas pelas quais os diretores do Grupo Escolar Lauro Müller se apropriaram das demandas educacionais do estado de Santa Catarina, à época, por meio do ensino de história - será necessário estabelecer dois pontos centrais de antemão, qual a motivação da criação dos Grupos Escolares e qual o local dos diretores destas instituições públicas.

\section{A modernização na escola: os grupos escolares}


Os grupos escolares eram construídos nas maiores cidades do Estado catarinense, que apresentassem uma demanda mínima de 300 alunos na idade escolar (TEIVE, 2008). Tal escolha justificava-se pelo alto custo da estrutura e manutenção dos grupos escolares. E para os alunos ingressarem no Grupo Escolar a lei determinava idade mínima de sete anos, ter: nome, sobrenome e bons costumes, não sofrer de nenhuma doença contagiosa ou repugnante e deveria comprovar que fora vacinada (SILVA, 2006). Entre as cidades escolhidas, os grupos eram construídos no centro, faziam parte do projeto republicano de delimitação dos espaços sociais e adequação a uma cidade aburguesada, não por menos, que Vera Lúcia Gaspar da Silva (2006), nomeia o grupo escolar como: "vitrine da república". Pois esse tipo de escola recebeu alunos que viveram ao redor do centro da cidade e, portanto, é uma população que estava ligada diretamente em seu cotidiano com as reformas urbanas ocorridas nos grandes centros.

Assim, os que não foram removidos, expulsos e impedidos de continuar vivendo nos centros urbanos no início do século passado, se mostravam afinados com as propostas do projeto modernizador da república. Então, os grupos escolares eram ferramentas institucionais para formarem os cidadãos da moderna polis brasileira, os seus hábitos culturais escolares cobravam esse tipo de atitude dos alunos. Mostra-se por excelência ser o tipo de escola criada para a República em sua estrutura, finalidades e idealizações.

À época tal ato, de erigir na capital catarinense o seu primeiro grupo escolar, foi amplamente divulgado pela imprensa. Através das folhas de jornais o público leitor pôde observar as comemorações e a magnitude da sua representação. Algo que o próprio governador deu destaque em seu relatório anual de 1912, citando membros importantes da elite política a época que disseram aos jornais: “O Grupo Escolar Lauro Müller (...) faz honra a nossa Capital.” (VIDAL RAMOS, 1912: 38); “A contemplação deste magnífico Grupo Escolar conforta o coração dos patriotas republicanos" (VIDAL RAMOS, 1912: 39); e continua:

Honra ao eminente Senhor Governador do Estado de Santa Catarina, pela feliz iniciativa da construção do belo edifício, onde hoje funciona o Grupo Escolar Lauro Müller, que recolhe, educa e prepara para uma nova época, 400 alunos, que serão amanhã os pregoeiros sinceros do seu alevantado civismo (VIDAL RAMOS, 1912: 39). 
Prestei a maior atenção à construção do edifício destinado a este grupo, assim como ao seu mobiliário e material de ensino, porque ele deve servir de modelo aos demais, que vão sendo fundados no Estado (VIDAL RAMOS, 1912: 40).

O último excerto traz as palavras escritas pelo Governador do Estado de Santa Catarina, Vidal Ramos (1910-1914), perante o Congresso de Santa Catarina no dia 23 de julho de 1912 após a inauguração do primeiro Grupo Escolar na capital catarinense, que havia contado "com a presença do Governador Vidal Ramos, do Inspetor Geral do Ensino, professor Orestes Guimarães, e de outras autoridades estaduais e locais" (DALLABRIDA; TEIVE, 2012: 39).

Diante desse acontecimento podemos perceber o que mexeu de fato com o imaginário da cidade, as mudanças bruscas do regime político brasileiro, na ainda recente República, a mudança do nome da cidade, na até então Nossa Senhora do Desterro, e a modernização que atropelava as estruturas culturais e sociais da cidade.

Na década de 1910 as reformas urbanas em Florianópolis já começavam a modernizar os ares do centro. As ruas eram calçadas, surgiam jardins, praças e começava a ter energia elétrica, entretanto, o trafegar de carregadores, as lavadeiras do riacho da Bulha, os vendedores ambulantes, as roupas e as gaiolas penduradas nas fachadas das casas já viravam hábitos e sujeitos não condizentes com o centro imaginado (NECKEL, 2003).

A instituição escolar é modificada nesse meio tempo de modernizações das cidades republicanas, seguindo o anseio do estado de Santa Catarina de se adequar a civilidade e ao aburguesamento. Para tal, foi decretada pelo governador Vidal Ramos e posta em prática em 1911 da nova proposta de instrução pública, visando extinguir os "velhos hábitos coloniais" colocando na "rota do progresso" (TEIVE, 2008). Assim, regulamentava a criação dos Grupos Escolares em quatro anos e com a função de escola de séries iniciais (SILVA; TEIVE, 2009). Portanto, o Grupo Escolar deve ser encarado como a escola feita na República e própria para a República.

O Grupo Escolar somente passa a existir com a delimitação entre o espaço das elites e o popular - entre os higienizados e os contagiosos, os com costumes ditos civilizados e os com costumes incivilizáveis- nas esteiras das modificações sociais e urbanas da cidade, com a 


\section{Em Tempo de Mistónias}

mudança que se almejava culturalmente, criar um indivíduo patriótico, higienizado e com disciplina de trabalho. Não por menos que eles serão situados no centro da cidade, como é o caso do Grupo Escolar Lauro Müller, dentro do cordão de isolamento do Boulevard Hercílio Luz, perto do Palácio do Governo, da Catedral Metropolitana, e com propostas pedagógicas modernas, o que reflete em sua mobília e arquitetura imponente, como o próprio Vidal Ramos destaca em seu discurso. Sendo o Grupo Escolar Lauro Müller uma escola voltada para uma parcela seleta da população florianopolitana, os que se enquadravam como cidadãos desejados na moderna Florianópolis.

\section{As reformas do efetivo escolar: o local do Diretor}

Para ser posto em prática tal pensamento modernizador em Florianópolis, o governador Vidal Ramos recorre ao então diretor Orestes Guimarães para implementar as mudanças necessárias na instituição. Guimarães havia sido contrato pelo governo catarinense em acordo com o governo paulista, entre os anos de 1907-1909 para ser diretor do Colégio Municipal de Joinville, que mais tarde viria a se tornar o primeiro Grupo Escolar do Estado (SILVA, 2006). No interim de colocar em prática as reformas modernizadoras da educação em Joinville, o Professor Orestes Guimarães ganhou o prestígio necessário para ser convidado para assumir o cargo de Diretor Geral da Instrução Pública.

A reestruturação na educação catarinense teve como meta reformar as Escolas Normais -formadoras de profissionais da educação-e as Escolas Isoladas -grande maioria do colégio e destinado ao centro rural-, implantar as Escolas Complementares -ensino entre as séries iniciais e os cursos de especialização- e os Grupos Escolares -instituição relativa aos primeiros quatro anos de ensino (DALLABRIDA; TEIVE, 2012).

A criação dos Grupos Escolares foi bastante restrita no Estado e na localização da cidade, foram criados sete instituições desse tipo que ocupavam as principais cidades do Estado: Joinville, Florianópolis (esta com dois Grupos Escolares), Blumenau, Itajaí, Lages, Laguna; para dirigi-las foram contratados normalistas formados no Estado de São Paulo (DALLABRIDA; TEIVE, 2012).

Inaugurado em 24 de dezembro de 1912, o Grupo Escolar Lauro Müller contou com festejos e a presença do Governador Vidal Ramos, Orestes Guimarães e autoridades locais e 


\section{Cm Tempo de Mistónias}

estaduais (SILVA, 2006; DALLABRIDA; TEIVE, 2012). Mas, principalmente, essa abertura do Grupo Escolar Lauro Müller contou com uma transformação essencial para este texto, a criação do cargo de Diretor Escolar; distinguindo-se das Escolas Isoladas pelo cargo de diretor, a nova posição na hierarquia institucional dava força à figura do diretor que era o mais alto representante do Governo no cotidiano escolar (DALLABRIDA; TEIVE, 2012).

À época, as funções de Diretor Escolar iam desde o zelo pelo patrimônio público investido na educação, passando pela nomeação de funcionários, até a fiscalização do trabalho, isso sem contar que ministrava aulas demonstrativas de acordo com os métodos modernos, sendo, portanto, condutor da ação pedagógica e dos conteúdos no Grupo Escolar (SILVA, 2006; DALLABRIDA; TEIVE, 2012). Além, de todo esse destaque na hierarquia organizacional da instituição escolar, o cargo de diretor se mostra um lugar de destaque pelas possíveis promoções para, por exemplo, a função de inspetor escolar que primava por diretores (SILVA, 2006).

\section{O álbum}

De acordo com Vera Lucia Gaspar da Silva, a nova organização da escrituração escolar deveria preencher documentos ordinais de forma minuciosa e, por consequência, como deveria ser lembrada. No conjunto de livros a serem preenchidos a autora destaca: "livro para registro do ponto, do inventário, de visitas das autoridades, de compras, de honra para alunos, de pena para os alunos, de avisos, de promoção, de correspondência, de termos de compromisso, nomeações, licenças, remoções, de chamada" (SILVA, 2006: 366).

Porém, depois de preencher um dia inteiro de documentos, acompanhar aulas, a utilização dos métodos de ensino, fiscalizar o trabalho higienizador dos demais funcionários, enfim, acompanhar todo o cotidiano escolar de perto, sem contar com as preocupações e tarefas de um cotidiano comum a pessoas de sua época, mesmo assim, o diretor Luiz Pacífico das Neves dedicou tempo e vontade para criar o Álbum do Grupo Escolar Lauro Müller.

Com isso, questiono quais forças o envolviam para tal ato de guardar o cotidiano escolar, ainda que de modo diferente aos oficiais. Seria essa questão apenas respondida pela importância, já demonstrada, do seu cargo para a sua época? Seria pela própria imagem que se fazia à época do Grupo Escolar Lauro Müller? Seria pela crença em seu trabalho civilizador 


\section{Cm Tempo de Mistónias}

realizado no Grupo Escolar? Enfim, o que se deixa transparecer nessas atitudes tomadas pelos diretores do Grupo Escolar? Tais questões talvez nunca cheguem perto de serem respondidas, o que não nos tira o prazer da tentativa de entender o que se passava no imaginário daquelas pessoas.

O livro é descrito por seus autores/atores como Álbum do Grupo Escolar Lauro Müller, apesar de não ser parecido com o tradicional álbum de fotografia familiar, de certa maneira se entende o que o primeiro autor quis significar com "Álbum". A palavra de origem latina álbum tem como uns dos seus significados "livro artisticamente encadernado que se destina à coleção de retratos; livro para receber desenhos, poesias, pensamentos, lembranças de pessoas amigas ou de família”(D’OLIVEIRA, 1977), visando manter vivas as lembranças. Isso porque nas páginas e mais páginas que se seguem, o “Álbum” é preenchido com recortes das reportagens que saíam em diversos jornais da época relativos ao Grupo Escolar Lauro Müller e também com os convites das festividades escolares, patrióticas ou não; formando uma espécie de imagens lançadas pela imprensa e pelos organizadores da festa ao público leitor sobre o Grupo em si, um retrato dos momentos em que a instituição passava. Sendo por último organizado, obviamente, caso se tenha em mente que se recortava e colava de acordo com as manchetes de jornais diários referentes ao grupo escolar, de forma cronológica. Assim, seria possível seguir o cotidiano e as transformações escolares como um álbum de família, resguardando o cotidiano, os acontecimentos marcantes e, enfim, o que subjetivamente merecia se tornar uma memória, do esquecimento.

$\mathrm{O}$ ato de guardar os recortes de matérias relativas ao Grupo Escolar segue na linha do que as autoras Ana Chrystina Venancio Mignot e Maria Teresa Santos Cunha, assinalam em seu trabalho de maneira exemplar: "guardar consiste em proteger um bem da corrosão temporal para melhor partilhar; é preservar e tornar vivo o que, pela passagem do tempo, deveria ser consumido, esquecido, destruído, virado lixo" (CUNHA; MIGNOT, 2006: 41).

Um ato de guardar que nesse caso se confunde entre o cotidiano administrativo desses diretores com o se cotidiano corrente (CUNHA; MIGNOT, 2006). O material recebe notícias que foram retiradas em dias de feriado, em sábados e domingos, dias que não necessariamente estariam ligados ao cotidiano administrativo, mas que ganham vez nas páginas do "álbum". Também se nota a dedicação dada ao arquivamento, não simples notícias grudadas às laudas, 


\section{Em Tempo de Mistónias}

mas são cuidadosamente postas: há entre as notícias linhas retilíneas separando-as, o nome do jornal retirado, a data, a capa, a letra caprichosa, o carimbo do grupo escolar e a assinatura do $1^{\mathrm{o}}$ diretor do colégio.

Assim, vai se delineando uma possível resposta para a apropriação que os diretores do colégio fizeram do ensino de história. Conseguimos, dessa forma, entender como o diretor do Grupo Escolar Lauro Müller fazia-se cumprir uma nova forma de ensino e, principalmente, pelo tipo de material recolhido, o ensino de história. Um documento não oficial nos deu a possibilidade de entender as relações que os diretores fizeram com o ensino, ainda que de alguma forma os desfiles patrióticos fossem emanados do Estado, se percebe a receptibilidade dos diretores. Eles não os guardam sem ter um motivo. Percebe-se como os diretores, enquanto agentes da história, e como tal, poderiam ou não ter seguidos as normas que o Estado prescreveu.

Deve-se ater, por conseguinte, que o Estado, ao redigir um decreto prescrevendo a mudança ou adição de determinadas disciplinas e os estudos a que elas comportam, acaba por estabelecer transformações de costumes, valores morais e comportamentais aos seus alunos; ou seja, está realizando um pretenso trabalho de normatização de concepções. Sobre a idealização do novo homem que se busca para essa sociedade, vale ressaltar que "não pode ser analisado fora da cultura política, das relações sociais e de poder que marcam interesses diversos distribuindo poderes em tempos e espaços delimitados historicamente" (SILVA, 2011: 252). Esse movimento de lutas, perdas e ganhos formarão o discurso do ideal para determinada época, reverberando, logicamente, nos documentos oficiais, podendo ou não ser cumprida, com uma liberdade, ainda que pequena.

Porém, o grupo social formado, nesse texto, por diretores que se mostram envoltos em uma sociedade que os mantêm com uma parcialidade de liberdade, "mas não fora, das limitações dos sistemas normativos prescritivos e opressivos" (LEVI, 2011: 137). O que leva a crer que toda a ação cotidiana é um jogo de constantes negociações, escolhas, manipulações de uma pessoa (LEVI, 2011); portanto, os documentos arquivados em forma de "álbum", contribuem para uma reconstrução desses aspectos, mesmo que "diante de uma realidade normativa que, embora difusa, não obstante oferece muitas possibilidades de interpretações e liberdades pessoais" (LEVI, 2011: 138). Depara-se com diretores que com a sua certa 
liberdade - dada pelo documento não oficial e, portanto, não sendo obrigatório a se preencher ou se quer ser feito- construíram uma imagem patriótica e gloriosa do grupo escolar.

\section{O ensino de história: representação e apropriação}

Para o texto, como já foi percebido, tem a sua importância argumentativa sobre as documentações encontradas dentro do Album do Grupo Escolar Lauro Müller. Já se falou o que era guardado, e aqui tenta-se colocar em discussão que esse material guardado representava para o grupo dos diretores. Assim frisa-se na ideia de que o ato de guardar vai para além do simples recorte, mas assume o significado de reter o ideal de educação e professor. Modos pelos quais foram apropriados do discurso do Estado e que essas pessoas se viam fazer parte. Foge-se da perspectiva macro para observar quais discursos do Estado faziam sentido a esse grupo intermediário, entre os professores e os dogmas estatais, que apesar de ter uma posição privilegiada no cotidiano educacional, são deixados de lado.

A tríade do texto se mostra presente nesses recortes colados às páginas do Álbum. História, moral e patriotismo seguem e são percebidos nas escolhas de representação da escola e do seu ideal de educação. Não à toa são fixados datas nacionais, grandes vultos nacionais, festividades pátrias, os convites e participações, tanto de catarinenses ilustres quanto dos próprios alunos. Os hinos e cantos da pátria e outras cerimonias simbólicas da pátria e do republicanismo ecoam por vezes do Álbum.

Os recortes são conexos à parte do que seria os limites principais das aulas de história como a biografia exemplar -história magistra vitae- e os símbolos pátrios já elencados. Portanto, para falar em apropriação e representação de si, por parte dos diretores, é notório elucidar o que o Estado almejava com o ensino da história -e a sua confusão com ensino de amor à pátria.

No Grupo Escolar estava proposto para o ensino de história como está em destaque nos programas escolares em notas para o professor:

O professor não deve perder oportunidade para salientar os principais fatos que demonstrem a união dos brasileiros contra as usurpações pelos estrangeiros. (SANTA CATARINA, 1914: 52).

O professor deve lembrar-se de que a História Pátria é um dos principais elementos da educação do povo. Aproveite, por isso, a oportunidade para 
despertar nos alunos sentimentos de são patriotismo. (SANTA CATARINA, 1928: 31).

A disciplina de história era percebida como parte de um projeto modernizador do Brasil através da educação cívico-patriótica, assim, o passado imperial necessitava ser reescrito, para ser criado um futuro coletivo republicano e moderno (SILVA, 2011).

Narrar sucintamente os principais costumes dos selvagens. O mesmo tipo de narração para comover os alunos para a questão das invasões extrangeiras, mostrando que os brasileiros sempre ficaram unidos contra a tentativa de conquistar o Brasil. As invasões são: de franceses, Maranhão e Rio, holandeses, Pernambuco, espanhois, Santa Catarina, ingleses, Rio grande e Trindade (ênfase meu). (SANTA CATARINA, 1920:.51).

Resumir traços biográficos de Colombo, Cabral, Tomé de Sousa, Duarte da Costa, Mem de Sá, Caramuru, José Anchieta, Camarão, Henrique Dias, André Vidal de Negreiros, José Bonifácio, Feijó, Ozório, Caixias, Barroso, Deodoro e Benjamin Constant (ênfase meu). (SANTA CATARINA, 1914: 53). $7^{o}$ Resumir traços biográficos de Colombo, Cabral, Tomé de Sousa, Duarte da Costa, Mem de Sá, Caramuru, José Anchieta, Camarão, Henrique Dias, André Vidal de Negreiros, José Bonifácio, Feijó, Ozório, Caixias, Barroso, Deodoro e Benjamin Constant, Rio Branco e de outros vultos nacionais. Catarinenses ilustres (ênfase meu).(SANTA CATARINA, 1920:.30).

Pelos excertos também retirados dos programas escolares dos Grupos Escolares, podese perceber a continuidade e quão importante era para o regime republicano as biografias de patriotas almejando o "são patriotismo" de sua população. Entre as décadas de 10 e 20 se mantêm a história magistra vitae como forma de inculcar o patriotismo republicano.

A VISITA ESCOLAR: Nessa visita, o Sr. Dr. Felippe Schmidt [senador por Santa Catarina à época] teve ocasião de observar quanto de benéfica e útil é a patriótica remodelação do ensino (Álbum do Grupo Escolar Lauro Müller, 1912-1960).

Dada a tradição dos encartos que produzem as festas d'aquele grupo, a de domingo será provavelmente mais uma a augmentar aquelles encantos, despertando a alegria e o espírito de civismo nos corações infantis (Álbum do Grupo Escolar Lauro Müller, 1912-1960).

Collocação do retrato do Exmo. Sr. Coronel Vidal Ramos, digníssimo Governador do Estado, no Gabinete do Diretor: Apezar da chuva impertinente que tamborinava incessante por toda a nossa 'Urbus', uma selecta assistencia affluiu ao edificio do Grupo Escolar Lauro Müller, afim 
de assistir mais uma consagração do mérito, do valor real do nosso querido chefe, o Exmo. Sr. Coronel Vidal Ramos (Álbum do Grupo Escolar Lauro Müller, 1912-1960).

GRUPO LAURO MÜLLER: a festa comemorativa do $2^{\circ}$ aniversário, cuja instalação o Exmo. Sr. Coronel Vidal Ramos como homenagem a gloriosa data de 24 de Maio, marcou para esse dia, afim de ensinar as gerações que venham surgindo o respeito e a gratidão pelos heroes que se impuzeram a gratidão da Patria amada (Álbum do Grupo Escolar Lauro Müller, 19121960).

A isso vale acrescentar duas coisas, a primeira se deve ao fato de ser atribuído ao professor por meio da legislação do programa escolar de 1928, os exemplos biográficos locais, tanto de "catarinenses ilustres" como de ex-alunos.

Nome do estabelecimento; dados biográficos de seu patrono e de seu creador; data da inauguração, serviços que tem prestado; directores que mais houveram cooperador pelo desenvolvimento do grupo; antigos alunos do estabelecimento que depois se distinguiram na vida prática (SANTA CATARINA, 1928: 19).

A segunda é que educação cívica ou patriota proposta para a época "deveria preparálos pela assimilação de valores, tendo-se por exemplo os protagonistas que contribuíram para a formação da sociedade"(VIEIRA, 2012: 327). Logo, ao recortar e guardar os diretores estavam por reter do esquecimento métodos de ensino patrióticos pelos quais se viam como parte integrante e realizadora.

Já entre os jornais recolhidos e cuidadosamente trabalhados para agrupar junto a outras memórias de papel, destacam-se as festividades cívicas e do próprio calendário anual do grupo escolar; entre as festividades são comemoradas e guardadas no Album: homenagem ao governador Vidal Ramos, inauguração do retrato do governador Vidal Ramos, festival de encerramento das aulas, independência ( 7 de setembro), festa da Bandeira (19 de novembro), festa da inauguração do Grupo Escolar (24 de maio), Descobrimento do Brasil (3 de maio), festa da Liberdade dos Povos (13 de julho) e festa de Natal (24 de dezembro). Sendo que em ambos recortes, de convites das festividades e a notícias de jornais das festividades que haveriam de ocorrer ou que já haviam acontecido, mostram na maioria apenas como se passou os atos das festividades. São narrativas que explanam as execuções de hinos, os horários e os 
atos feitos, no máximo atribuem congratulações a uma declaração das pessoas vinculadas aos cargos mais altos da hierarquia educacional ou ao próprio governador.

No Grupo Lauro Müller em comemoração ao dia da Bandeira: Ao meio dia formados todos os alumnos, no pateo desse estabelecimento de Instrução foi hasteada a Bandeira, cantando os alunos os hymnos à Bandeira, Nacional e do Estado (Álbum do Grupo Escolar Lauro Müller, 1912-1960).

3 de Maio: (...) realce, pois são sempre encantadoras e revelam não só os esforços dos dignos diretor e corpo docente como o aproveitamento dos alumnos, os quaes em todas as festas escolares e especialmente na comemoração das nossas mais gloriosas datas, vibram de patriótico enthusiasmo, demonstrando o avigoramento dos sentimentos cívicos que lhes são incutidos nos tenos corações e desabrochantes inteligencias (Álbum do Grupo Escolar Lauro Müller, 1912-1960).

O 7 de Setembro: Á frente desse movimento de patriotismo, dessa enecquivoca prova de civismo, dessa cultural preparação dos nosso grandes destinos, estiveram os grupos escolares(...) (Álbum do Grupo Escolar Lauro Müller, 1912-1960).

Confunde-se, desse modo, as aulas patrióticas nos horários estabelecidos pelo ensino de história e os ensinamentos patrióticos para além da aula. O aprendizado dos deveres patrióticos acontecia tanto fora como dentro dos muros da instituição escolar. Não há como saber quais deles prevaleciam, mas o seu ensinamento não há um "fora" ou "dentro", neste caso.

No ato de narrar uma história pátria por meio de festas, símbolos e biografias, novas personagens e novas imagens de antigas personagens emergiram, revisitando-os para criar uma história brasileira baseada no republicanismo. Heróis que agora eram trajados à nova moral republicana, em outras palavras, acabavam por dar ares a personagens "históricos" de bons patriotas. Por mais que essas personagens fossem de épocas dispersas, a sua narrativa biografia os unia pela sua vida cívica. (VIEIRA, 2012). Elementos que se deixam perceber no “álbum” dos diretores do Grupo Escolar Lauro Müller.

As personagens narradas também eram motivos das festividades escolares, porém, deve-se ater aos símbolos que nelas estavam inerentes. Como os hinos nacionais e estaduais, cantos: os mosquitinhos, no mar, festa das árvores, hino do $4^{\circ}$ Centenário de independência, hino a bandeira, o marinheiro. Atendo-se para que "o recorte da história nacional, com seus desfiles de feitos e heróis, acabava por participar do trabalho de nacionalizar os cidadãos pelo 
ensino e exaltação daquilo que seria o seu passado comum" (SILVA, 2011: 264). Ou seja, músicas e datas que estão interligadas com a patriotização do cidadão almejado, forjando "dentro" e "fora" das aulas de história um ensino voltado para a criação de um laço identitário nacional.

A educação por meio dos desfiles e o ensino nas aulas de história "foram mediadoras centrais na construção cívica, política, social e cultural" (SILVA, 2011: 264), constituindo um importante papel para a disseminação e consolidação da história e patriotização do cidadão.

A festividade era o momento em que a escola se mostrava para a cidade e os alunos eram os atores centrais. O local definido para as suas marchas ou apresentações mostrava o destaque que deveria ser dado às festividades, que normalmente ocorriam no prédio do grupo escolar ou na Praça XV de Novembro, marco central de Florianópolis. Como mencionava o convite para o dia da Bandeira: "Tenho a honra de convidar a V. S. e Exma. Família para assistirem a 'Festa Escolar' em homenagem a República e a Bandeira, a realizar-se às 17 horas do dia 19 do corrente, no edifício do Grupo" (Álbum do Grupo Escolar Lauro Müller, 1912-1960).

A organização, o treinamento dos cantos, o treinamento do desfile, o vestuário, devem ser percebidos como um esforço para se adequar a um ideal da festividade e que transporta em si símbolos polissêmicos.

Assim, as festas escolares devem ser percebidas como uma linguagem coletiva que revela diversos planos simbólicos "apreendidos por aqueles que delas têm algum tipo de participação, quer sejam como organizadores, personagens ou expectadores” (BENCOSTTA; PEREIRA, 2006: 385). No caso, os diretores eram ao mesmo tempo organizadores do evento e expectadores, sem mencionar guardadores do episódio, talvez tocados por sentimentos de dedicação, apego, anseio e afeto mais do qualquer outro no local. Enquanto guardadores, discentes e inspetores da educação do Grupo Escolar Lauro Müller, o projeto republicano, modernizador e nacionalista, sem dúvida os tocou em seu cotidiano administrativo.

Assim, evidencia-se que esses materiais guardados foram onde os diretores se viam, se representavam e o que concordaram ser importante para o ensino público republicano. Devese lembrar que o Album criado, a princípio aceitaria tudo. Aceitaria tudo porque forma um material que não têm uma legislação e regulamentação especificando como deveria ser

\footnotetext{
Em Tempo de Histórias

Publicação do Programa de Pós-Graduação em História da Universidade de Brasília (PPGHIS/UnB)

No. 23, Brasília, ago. - dez. 2013 ISSN 2316-1191
} 


\section{Cm Tempo de Mistónias}

preenchido, pois é um documento não oficial. Portanto, as vozes ecoadas por meio dele foram escolhidas entre uma gama inúmera do que poderia ser registrado da escola.

\section{O que guardar? Símbolos apropriados do discurso do Estado}

Apesar de como já foi disposto anteriormente, guardar com tanto carinho e capricho as notícias do cotidiano do Grupo Escolar Lauro Müller, não pode ser responsabilizado apenas pelo fato de ser um cargo hierarquicamente alto na hierarquia da escola. Mesmo porque quantos diretores de diversos grupos escolares houve? E quanto destes preencheram com paciência um documento não oficial relativos à escola? Portanto, indo ao encontro de Cunha e Mignot(2006), pode-se pensar que tal fonte serve para realçar a sua importância - ainda que, esse tipo de documento utilizado seja visto como menor na história em comparação a revistas, livros, programas escolares, leis e decretos - para a formulação e aplicação das leis no cotidiano de trabalho desses diretores. Por conseguinte, esse tipo de fonte utilizada se mostra confluente com "a valorização das experiências de pessoas que participam ativamente delas e, especialmente, para o sentido e o significado que lhes outorgam, pela via do escrito" (CUNHA; MIGNOT, 2006: 53).

Enfim, tal trabalho se propôs a pensar o ensino de história e a apropriação dela pelos agentes burocráticos do Estado, responsáveis por administrar o Grupo Escolar, fiscalizar as aulas, os professores e professoras, as matérias, o modo de serem ensinadas e fiscalizar também os próprios cortejos e desfiles públicos. Atribui-se a questão de quem está reformulando e pondo em prática tais escolhas do Estado, tratando em uma perspectiva que lida com a história dos grupos intermediários, não uma história dos grandes homens e nem uma história vista de baixo. Mas demonstrando como foi atribuída a época nos espaços da cultura escolar o ensino de história e os principais agentes realizadores de tamanha missão que se punha no momento: a patriotização do cidadão republicano.

Apesar de os diretores, como deixa transparecer o “álbum”, não tratarem de uma maneira adversa aos padrões impostos pelo Estado através de um código de condutas e o que se deve atingir. Pode-se pensá-los como idealizadores junto ao Estado de tamanha proposta ou como um grupo que reapropriou o projeto de cidadão almejado pelo Estado. Uma apropriação que só se mostra parcialmente pelos elementos que foram guardados no "álbum". Nele só 


\section{Com Tempo de Mistónias}

houve espaço para as notícias de festividades, não há nele questões referentes a outro tipo de cotidiano fora o das festas.

As mudanças ocorridas posteriormente não tiveram o significado esperado por parte do Estado ao grupo social dos diretores. Um segundo silêncio que se mostra ao lidar com o “álbum”, porém, neste se podem articular as delimitações que os diretores viam no projeto, dando sentido, voz e continuidade apenas às festas escolares. Assim sendo, poderia se dizer que foram tais elementos culturais que mais se destacaram na vida escolar a estes profissionais da educação durante as duas primeiras décadas. Contudo, notou-se a apropriação desses indivíduos e como eles dissuadiram a outras propostas do Estado; durante a década de 1920 e 1930 se deve lembrar a questão da higienização da sociedade nessa época.

O Brasil da República na sua epopeia de corrigir, modificar e criar novos hábitos para a cultura brasileira se via também responsável pela viabilização do país, ou seja, ao mesmo tempo em que se sanitarizava as cidades, se sanitarizava o corpo. Na ânsia de civilizar a pátria, foi delegada a escola e os seus profissionais atuarem sobre "os corpos e as mentes das crianças, especialmente as mais pobres, modificando os hábitos e as maneiras culturalmente aprendidas, impondo condutas e práticas corporais autorizadas pelas novas normas de civilidade" (TEIVE, 2008: 96).

O corpo não poderia correr o risco de cair ou continuar nos "vícios" que havia no Império, pois, caso a nação não se comprometesse a cumprir os rigorosos procedimentos, estaria fadada ao fracasso, sendo inviável como nação, por conseguinte, deveria ser higienizado, civilizado e moralizado. (FLORES, 2007). Os argumentos médicos, imbuídos como verdades, ensinavam à população "como melhor se conduzir com vistas à polidez e à civilidade, refreando os instintos que lembravam a animalidade e cultivando modos de ser distintos e agradáveis a si mesmo e aos outros"(STEPHANOU, 2004). Estes cuidados com a estética, asseio pessoal, a intimidade, a sexualidade, enfim, o cuidado com o corpo, pode ser lido como mantenedor de um cidadão laborioso e de convívio urbano, o símbolo do progresso almejado pela república.

Uma tarefa árdua de readequação das subjetividades pelo viés modernizador e racional dos discursos médicos. O corpo que segue as normas higienizadora se torna o único tipo possível de cidadão produtivo para o país, não sendo passível de sofrer dos males causados 
pela "mestiçagem", criminalidade, loucura, entre outros problemas patológicos apontados pela ciência moderna que havia levado o país e a sociedade a esse Estado deplorável (FLORES, 2007). Portanto, corpo e nação estão profundamente ligados quando se trata de políticas públicas, já que é no corpo e através dele que se forja a nação desejada (FLORES, 2007).

Porém, como tais agentes da instituição escolar não ajuntaram papéis relativos as propagandas viris das aulas de educação física ou de fotos que mostravam os corpos dos alunos individualizados, exercícios calistênicos, raça, branqueamento da população, ou alunos higienizados, muito menos fora guardado objetos relativos a manuais de civilidade, objetos relativos às aulas de higiene e do "Pelotão de Saúde". Propõe-se que tal discurso do Estado não teve tanta aceitação em seu cotidiano administrativo como o caso do nacionalismo e patriotismo.

O ensino de história patriótico foi onde esses indivíduos se viram, guardaram e o protegeram do esquecimento; fazendo este trabalho tão bem que quase 100 anos depois o "álbum" chegou à mão do pesquisador. Outros tantos projetos de reformular a cultura escolar por não chegarem à mão através de tais diretores podem evidenciar a sua vontade por guardar e fazer sentido apenas os símbolos de patriotismo e republicanismo. Enfim, enquanto diretores e membros responsáveis pela educação, fiscalizando as aulas dos professores ou as dando, sem dúvida pode ter sido esse tipo de valor cobrado e proferido. Algo apenas possível de se compreender ao diminuir a escala da pesquisa.

\section{Referências}

Álbum do Grupo Escolar Lauro Müller, 1912 - 1960. Acervo do Museu da Escola Catarinense.

ALBUQUERQUE, Durval Muniz de. História: a arte de inventar o passado: ensaios de teoria da história. São Paulo: Edusc, 2007.

ARTIÈRES, Philippe. Arquivar a própria vida. Estudos históricos. Rio de Janeiro, vol. 11, n. 21, p. 9-34, 1988. BENCOSTTA, Marcus Levy Albino; PEREIRA, Ana Paula Martins. História, cultura e sociabilidades: representações e imagens das festas escolares (Curitiba, 1903-1971). Disponível em: http://www.faced.ufu.br/colubhe06/anais/arqivos/Marcus\%20Levy\%20Albino\%20Bencostta.htm.

Acessado em 27 de abril de 2012. Sexta edição do congresso Luso-Brasileiro de História da Educação: Uberlândia, Minas Gerais, 2006.

CUNHA, Maria Teresa Santos. Uma biblioteca anotada: caminhos do leitor no acervo de livros escolares do Museu da Escola Catarinense (Décadas de 20 a 60/século XX). Florianópolis: Imprensa Oficial do Estado de Santa Catarina-UDESC, 2009. 
DALLABRIDA, Norberto; TEIVE, Gladys Mary Ghizoni. A escola da república: os grupos escolares e a modernização do ensino primário em Santa Catarina (1911-1918). Campinas: Mercado de Letras, 2011.

FARIA FILHO, Luciano Mendes de, et. al. A cultura escolar como categoria de análise e como campo de investigação na história da educação brasileira. Revista Educação e Pesquisa, São Paulo, vol. 30, n.1, 139-159, jan./abr. 2004.

FLORES, Maria Bernadete Ramos. Tecnologia e estética do racismo: ciência e arte na política da beleza. Chapecó: Argos, 2007.

GOMES, Ângela de Castro. "Escrita de si, escrita da história - a título de um prólogo". In: Escrita de Si, Escrita da História. GOMES, Ângela de Castro (org.). Rio de Janeiro: Editora FGV, 2004, p. 7 - 24.

LEVI, Giovanni. Sobre a micro-história. In: A Escrita da história: novas perspectivas. BURKE, Peter (org.); Tradução Magda Lopes. São Paulo: Editora UNESP, 2011, 135-164.

MIGNOT, Ana Chrystina Venancio; CUNHA, Maria Teresa Santos. Razões para guardar: a escrita ordinária em arquivos de professores/as. Revista Educação em Questão. Natal, vol. 25, 2006.

NECKEL, Roselane. A República em Santa Catarina: modernidade e exclusão (1889-1920). Florianópolis: Editora da UFSC, 2003.

SANTA CATARINA. Programa de Ensino dos Grupos Escolares. Aprovado pelo decreto n.2.218, de 24 de Outubro de 1928. Florianópolis: Tipografia da Livraria Moderna, 1928. Acervo do Museu da Escola Catarinense.

SANTA CATARINA. Programa de Ensino dos Grupos Escolares. Aprovado pelo decreto 796 de 2 de Maio de 1914. Florianópolis: Tipografia da Livraria Moderna, 1914. Acervo do Museu da Escola Catarinense.

SILVA, Cristiani Bereta da. "Os programas de ensino catarinenses na primeira república e o ensino de História". In: MORGA, Antônio Emílio (org.). História, cidade e sociabilidade. Itajaí/SC: Ed. Casa Aberta, 2011.

SILVA, Vera Lucia Gaspar da. "Vitrines da República". In: Diana Gonçalves Vidal (org.). Grupos Escolares: cultura escolar primária e escolarização da infância do Brasil (1893-1971). Campinas: Mercado de Letras, 2006.

SILVA, Vera Lucia Gaspar da; TEIVE, Gladys Mary Ghizoni. Grupos Escolares: criação mais feliz da República? Mapeamento da produção em Santa Catarina. Revista Linhas de Programa de Pós-Graduação em Educação, Florianópolis, vol.10, n. 1, p.31-53, ja./jun. 2009.

STEPHANOU, "Maria. Saúde, higiene e civilidade em manuais". In: III Congresso Brasileiro de História da Educação, 2004, Curitiba/PR. A Educação Escolar em Perspectiva Histórica. Curitiba/PR: Universitária Champagnat, 2004.

TEIVE, Gladys Mary Ghizoni. "A escola normal catarinense sob a batuta do professor Orestes Guimarães". In: DALlABRIDA, Norberto (org.). Mosaico de escolas: Modos de educação em Santa Catarina na Primeira República. Florianópolis: Cidade Futura, 2003, p. 221-252.

TEIVE, Gladys Mary Ghizoni. "Uma vez Normalista, sempre Normalista": cultura escolar e produção de um habitus pedagógico (Escola Normal Catarinense- 1911/1935). Florianópolis: Ed. Insular, 2008.

VIDAL RAMOS. Mensagem do governador, 1912. Santa Catarina: Acervo do Arquivo Público de Santa Catarina (APESC), 1912.

VIEIRA, Cleber Santos. Civismo, República e manuais escolares. Revista Brasileira de História. São Paulo, vol. 32, n. 63, p. 325-340, 2012. 